\title{
Guideline adherence: How do boards of directors deal with it? A survey in Dutch hospitals
}

\author{
Louise H.K. Blume*1,2, Nico J.H.W. van Weert ${ }^{3}$, Jamiu O. Busari ${ }^{1,4}$, Diana Delnoij ${ }^{2,5}$ \\ ${ }^{1}$ Zuyderland Medisch Centrum, Sittard, Netherlands \\ ${ }^{2}$ Tilburg School of Social and Behavioural Sciences, Tranzo, Scientific Center for Transformation in Care and Welfare, Tilburg \\ University, Tilburg, Netherlands \\ ${ }^{3}$ Q! B.V., Nijmegen, Netherlands \\ ${ }^{4}$ Department of Educational Development and Research, Faculty of Health, Medicine and Life Sciences, University of Maastricht, \\ Maastricht, Netherlands \\ ${ }^{5}$ National Health Care Institute, Zorginstituut Nederland, Netherlands
}

Received: May 9, 2016

DOI: $10.5430 /$ jha.v5n $5 \mathrm{p} 21$
Accepted: June 29, 2016

Online Published: July 6, 2016

URL: http://dx.doi.org/10.5430/jha.v5n5p21

\begin{abstract}
Objective: Adherence to guidelines is often low, as multiple barriers exist for guideline implementation. To tackle the implementation problem, awareness of the existence of guidelines is necessary for the health care process and setting as a whole. Purpose: Despite the importance of guidelines adherence, problems have been reported from hospitals in achieving this. This study gives insight into how boards of directors of general and specialist hospitals arrange the responsibilities for guideline adherence within their organisation, how they deal with guidelines for medical specialists and what opportunities exist for improvement.

Methods: A survey was sent to 116 Dutch hospitals in 2015. Thirty-nine responses were included in the study for further analysis (net response rate of 36\%). All data other than the open questions were analysed in SPSS using descriptives to answer the research question.

Results: The findings demonstrated that the distribution of responsibility concerning guideline implementation is problematic. The boards of directors used a variety of information sources to keep informed about the status of implementation of the guidelines for medical specialists, mostly through medical specialists' peer reviews (visits) and internal audits. The study revealed several opportunities for improvements, for example, that a national database is necessary with all up-to-date guidelines, whereby changes and news are distributed directly to hospitals and other stakeholders.

Conclusions: This paper offers recommendations for a thoughtful shift in distribution of responsibility, as in a more desired situation the ultimate responsibility of the board of directors would decrease and the responsibility of the medical specialists would increase.
\end{abstract}

Key Words: Guidelines, Hospitals, Board of directors, Adherence, Compliance

\section{INTRODUCTION}

Preventable harm is the third most frequent cause of patient death around the world and has partly been associ- ated with the inadequate adherence to hospital guidelines by health care providers. ${ }^{[1]}$ Consensus-based and evidencebased guidelines for diseases are continuously being devel-

\footnotetext{
*Correspondence: Louise H.K. Blume; Email: 1.blume@ zuyderland.nl; Address: Zuyderland Medisch Centrum, Sittard; Tilburg School of Social and Behavioural Sciences, Tranzo, Scientific Center for Transformation in Care and Welfare, Tilburg University, Tilburg, Netherlands. 
oped to improve the quality of care. However, adherence to these guidelines has been reportedly low, due to the presence of multiple barriers hindering implementation. ${ }^{[2]}$ The awareness of the existence of guidelines to ensure safe care has been identified as one of those barriers. ${ }^{[1,3]}$ We were interested in knowing whether boards of directors in Dutch hospitals are aware of the full scope of medical guidelines they are responsible and accountable for and wanted to find out how they act on them.

Up until now, problems with implementation have predominantly been investigated by examining one guideline at a time, per disease or case. Implementation strategies have been tested and retested to achieve better results, however, without taking overall contexts into account. ${ }^{[4]}$ To tackle the implementation problem as a whole, awareness of the existence of guidelines is necessary, not only for those on a single topic or disease but also for the health care process and setting as a whole. More attention needs to be directed to changing systems that support guideline implementation rather than those that focus on the behaviour of individual clinicians. ${ }^{[5]}$ This study, therefore, investigates what the current boards of directors' perspectives are on the governance structure concerning guideline adherence.

Pronovost suggested that guideline developers ought to shift their focus away from relying on the performances of individual clinicians towards systems that can support guideline implementation. This line of thinking aligns with the General System Theory that suggests problems can effectively be solved by using systems or a systems approach. ${ }^{[6,7]}$ According to this theory it is argued that when seeking a solution to a problem, it is important to consider all parts of an organisation or context in order to avoid repetition of the same activity or intervention. This is because it is impossible to resolve every problem at the local level alone or as isolated units. A hospital is a complex organisational system and consists of various activities with different levels of inputs, outputs and operational processes. Therefore, it is logical to assume that if hospital management considers all medical guidelines (input) as an entity rather than isolated units, then hospital management should be able to implement guidelines (processing) more efficiently in order to achieve good patient outcome (output) (see Figure 1). In our study, we will approach the hospital management as a system, which has inputs, processes and outputs.

As guidelines are continuously being (re-)designed and developed, hospitals constantly need to adjust their operational processes in order to be able to adhere to them. In the nursing and medical profession, specialisation is an autonomous process, which is a result of the expansion of medical knowledge.
Consequently, guideline development takes place within highly specialised professional subgroups. During implementation in a hospital, several guidelines have to be taken into account simultaneously, as the real situation is more complex than the fragmented specialisation in one guideline. Clinicians have to deal with patients suffering from multiple morbidities. At the same time, clinicians and managers have to translate requirements and processes described in a variety of guidelines into coherent rules, protocols and regulations. We want to know how boards arrange responsibilities for adherence within their organisation.

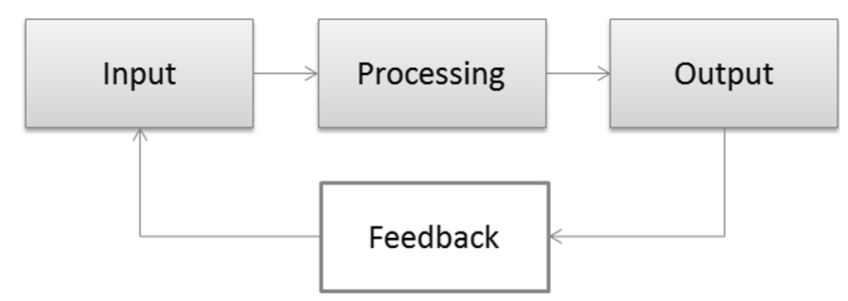

Figure 1. Hospital management as a system

The adoption and correct implementation of all quality standards within a hospital is the responsibility of the board of directors. Clinicians, being specialists within their own field and their respective scientific associations (are expected to) develop guidelines for their own disciplines and are also expected to adhere to them. We want to know how the board keeps informed about the implementation status of guidelines.

Dutch hospital board members are our object of study and we focus on medical guidelines within hospitals. This study examines how boards of directors of general and specialised hospitals in the Netherlands deal with guidelines for medical specialists, how they arrange responsibilities for adherence within their organisation, and what challenges or problems they experience in organising adherence. The insights from this research could be used to improve guideline usage in hospitals and policies regulating guideline adoption and implementation in hospitals. This study addresses the following research question and sub-questions: How do boards of directors of Dutch hospitals deal with guideline adherence?

(1) Do boards of director's experience problems in adherence with medical guidelines?

(2) What is the governance structure, i.e. how do boards: - arrange responsibilities for adherence within their organisation?

- keep informed about the implementation status?

(3) Is there a relation between the governance structure and the problems that boards experience? 
(4) What are the perceived opportunities for improvement?

\section{MeTHODS}

\subsection{Study design and participants}

We collected both quantitative and qualitative data to investigate the challenges Dutch hospitals face with regard to guideline adherence. The study was conducted in the Netherlands between March and June 2015. All hospital board members of the Dutch Hospital Association (NVZ), comprising a total of 116 health-care representatives, were invited to participate. The member organisations are either general, specialist or teaching hospitals. University Medical Centres were not invited.

\subsection{Survey}

The questions for this survey were developed based on an earlier Delphi study, ${ }^{[8]}$ using statements on which all participants agreed and using statements on which no one agreed. Questions were developed to assess the board of directors' understanding of guidelines and their responsibility for compliance. The questions were organised into four main categories. The first category focused on the problems experienced by the boards of directors, where we assessed the feasibility of guideline adherence, and the problems experienced by boards of directors on the distribution of responsibilities. The second category concerned questions to assess the governance structure. Questions were asked about the responsibilities for guideline adherence and how boards keep informed about the implementation status of guidelines. The third category included questions about the relation between the governance structure and the problems that boards experience. In the fourth category, board members were asked what the opportunities are for improvement.

The survey was pretested through five think aloud tests by non-participants of the study working in a hospital to test the usability. During a think aloud test participants are asked to talk aloud whatever thoughts come to their mind as they move through the survey. ${ }^{[9]}$ The aim is to detect design issues and improve the items that are observed as difficult. The outcome from a think aloud test was processed after each test before the following test took place.

After the test, the boards of directors received a digital questionnaire which consisted of 51 questions, using the webbased tool SurveyMonkey. Seven questions were open questions, nine questions were closed-ended questions with ordered response choices, two questions were dichotomous questions and 33 questions were Likert scale questions. Ten of the multiple choice questions had the possibility for entering comments in an open field, which was not compulsory.

Published by Sciedu Press

\subsection{Data collection}

The 116 contact persons for members of the NVZ received a digital invitation including the link to the survey. After four weeks, a reminder was sent. The participants were given the opportunity to enter their hospital name and their occupation for the analysis of the researchers. In total 56 responses were received, representing 54 Dutch hospitals, a response rate of $46 \%$. Participants who filled out less than $50 \%$ of the questions were excluded from the analysis $(\mathrm{N}=15)$, including empty submitted surveys $(\mathrm{N}=2)$. After exclusion, 39 responses remained, representing 39 Dutch hospitals, which were included in the study for further analysis, representing a net response rate of $36 \%$. For three questions, the open comment fields were coded and added to the original possible answers, as many responses corresponded to one of the previously given categories, together with an explanation. It seems as if participants wanted to specify why they chose one category, that's why we assume they often used the open comment field.

\subsection{Analysis}

First, we prepared the dataset for the 39 responses with SPSS and recoded the ordinal variables into dummy variables. All questions other than the open questions were analysed in SPSS using descriptives to explore differences between the distributions of responsibilities. If necessary, the open comments fields were coded and added to the original possible answers. Secondly, the chi-square was used to test whether two variables answers are related to each other, and we used it to answer whether the boards of directors experience problems in adherence to guidelines and what their governance structure is $(p<.05)$. For the first three research questions, the results of the experiences of boards of directors regarding responsibility were examined in contrast to other results of the survey (see Tables 1-3). Analyses were performed using IBM SPSS Statistics 21 and Excel.

\section{Results}

\subsection{Experiencing problems}

The majority of the boards of directors reported that they find it problematic to establish who is ultimately responsible for guideline adherence for medical specialists.

Table 1 compares the feasibility of a hospital's capability to assure medical specialists' guideline adherence in settings where problems are perceived versus those where none are experienced. The chi-square test showed $(1.44, p=.23)$ that no statistically significant association was found between the feasibility of hospitals ensuring medical specialists' adherence to all guidelines and the experience of problems with the distribution of responsibility. 
Table 1. Feasibility of guideline adherence versus experiencing problems with distribution of responsibility

\begin{tabular}{llll}
\hline \multirow{2}{*}{$\begin{array}{l}\text { It is feasible for hospitals to adhere to all } \\
\text { guidelines for medical specialists }\end{array}$} & \multicolumn{3}{c}{ Distribution of responsibility } \\
\cline { 2 - 4 } & Not problematic & Problematic & Total \\
\hline • Agree & $8(53 \%)$ & $7(47 \%)$ & $15(100 \%)$ \\
- Disagree & $7(33 \%)$ & $14(67 \%)$ & $21(100 \%)$ \\
Total: Chi-square: $1.44, p=.23$ & $15(42 \%)$ & $21(58 \%)$ & $36(100 \%)$ \\
\hline
\end{tabular}

Table 2. Reported distribution of responsibility versus experiencing problems with distribution of responsibility

\begin{tabular}{llll}
\hline & \multicolumn{3}{c}{ Distribution of responsibility } \\
\cline { 2 - 4 } & \multicolumn{1}{c}{ Not problematic } & \multicolumn{1}{c}{ Problematic } & \multicolumn{1}{c}{ Total } \\
\hline Experience with establishing responsibility - Total & $16(41 \%)$ & $23(59 \%)$ & $39(100 \%)$ \\
Responsible for discipline-specific guidelines Q9 & & & \\
- Medical specialists, professional associations from relevant speciality & $5(38 \%)$ & $8(62 \%)$ & $13(100 \%)$ \\
- Medical speciality society & $2(100 \%)$ & $0(0 \%)$ & $2(100 \%)$ \\
- Otherwise, namely & $9(43 \%)$ & $12(57 \%)$ & $21(100 \%)$ \\
Responsible for non-discipline-specific guidelines Q10 & $0(38 \%)$ & $3(100 \%)$ & $3(100 \%)$ \\
- Medical specialists, professional associations from relevant speciality & $1(50 \%)$ & & $2(50 \%)$ \\
- Medical speciality society & $2(50 \%)$ & $2(50 \%)$ & $4(100 \%)$ \\
- Board of directors & $12(39 \%)$ & $19(61 \%)$ & $31(100 \%)$ \\
• Otherwise, namely & $1(50 \%)$ & $1(50 \%)$ & $2(100 \%)$ \\
\hline
\end{tabular}

\subsection{Governance structure}

Two items were investigated in this section, focussing on the governance structure, i.e. how do boards: (1) arrange responsibilities for adherence within their organisation, and (2) how do they keep informed about the implementations status.

\subsubsection{Responsibilities for adherence}

The distribution of the responsibilities for discipline-specific and non-discipline-specific guidelines varied. The perceived problems were not clearly linked to the governance structure designed to allocate the responsibility for the implementation of guidelines (see Table 2).

In the majority of cases, the board of directors reported being responsible for guideline adherence. This was the case in 21 out of 39 hospitals in cases of discipline-specific guidelines and in 31 out of 39 hospitals for non-discipline-specific guidelines. However, in 13 hospitals, medical specialists were reported to be responsible for adherence to disciplinespecific guidelines in their own area of professional expertise.

In hospitals, where the responsibility was reported to lie with the board of directors, the number of respondents that experienced problems was slightly overrepresented. This was both the case for discipline-specific guidelines as well as for non-discipline-specific guidelines. More than half of the participants stated that the structure in their hospital is decentralised to ensure that guidelines for medical specialists are known by those responsible for their implementation (not in table). The ultimate responsibility is recorded in written form in 59\% of the hospitals.

As we already pointed out, $59 \%(n=23)$ of the boards of directors experience problems in the establishment of responsibility. We asked these 23 participants to specify what they find problematic in establishing the responsibility establishment for guideline adherence in an open field. The participants stated that it is almost impossible to verify adherence. Numerous $(n=10)$ participants reported that problems occur because they lack an overview of the guidelines. They stated that the number of guidelines was too large to be manageable for a hospital and one stated that their medical specialists report that it is not possible to be up-to-date in regard to all guidelines. Participants stated that part of the problem is that information about new or updated guidelines is not collected centrally within a hospital but decentralised.

\subsubsection{Keeping informed about the implementation status}

The participants stated that they used a variety of information sources to keep informed about the status of implementation of the guidelines for medical specialists, mostly through medical specialists' peer reviews (visits) and internal audits (see Table 3).

Based on the results of Table 3, we can see that in general there is no correlation between the way boards of directors inform themselves about the implementation status of 
guidelines and the degree to which they experience problems establishing responsibility for guideline adherence. However, boards of directors who rely on checks of adherence by external bodies such as the Inspectorate for Healthcare, IGZ, $(n=29)$ reported problems more frequently in the distribution of responsibility for guideline implementation (Chi-square $=4.66, p=.03$ ). There was a significant relationship between the board of directors who consulted the departments/speciality concerning the status of guideline adherence regularly (annually/quarterly) and the degree to which they experienced problems with distribution of responsibility (Chi-square $=3.813, p=.0508$ ).

In an open question, participants were asked what steps are taken if progress on guideline implementation is insufficient. They stated that they brainstorm with the internal stakeholders to put systems in place, demand accountability, address the insufficiency, and then support them in working towards improvements. Enforcement, sanctions, or supervision were reported as possible steps by a few participants.

\subsection{Is there a relation between the governance structure and the problems that boards experience?}

Table 4 compares the board of directors' experiences with the implementation of guidelines to their level of awareness about the stages of implementation for medical specialists. Twenty participants stated that the hospital board is informed of the guidelines for medical specialists that have priority within their hospital, but $14(70 \%)$ of those did experience problems in establishing the responsibility for guideline adherence. Five hospitals expressed through the open comments field that the awareness is limited, and one respondent pointed out: "The number of guidelines is so large that I do not dare to say that we are aware of all guidelines."

Table 3. The information source (multi-response question) of the board of directors on guideline implementation versus experiencing problems with distribution of responsibility

\begin{tabular}{|c|c|c|c|c|}
\hline \multirow{2}{*}{ Experiences with establishing responsibility } & \multicolumn{3}{|c|}{ Distribution of responsibility } & \multirow{2}{*}{ Chi-square $(p)$} \\
\hline & Not problematic & Problematic & Total & \\
\hline \multicolumn{5}{|c|}{ How does the board of directors inform itself on the status of implementation of guidelines for medical specialists? (multiple answers possible) } \\
\hline $\begin{array}{l}\text { - Through reports of peer reviews conducted by the medical } \\
\text { specialists }\end{array}$ & $14(39 \%)$ & $22(61 \%)$ & $36(100 \%)$ & $0.883(.34)$ \\
\hline - Through internal audits & $12(36 \%)$ & $21(64 \%)$ & $33(100 \%)$ & $1.927(.16)$ \\
\hline $\begin{array}{l}\text { - Through checks on medical specialists' adherence to } \\
\text { guidelines by external bodies such as the Inspectorate for } \\
\text { Healthcare }\end{array}$ & $9(31 \%)$ & 20 (69\%) & $29(100 \%)$ & $4.666(.03)$ \\
\hline $\begin{array}{l}\text { - The board of directors consults regularly (annually/quarterly) } \\
\text { with the departments/speciality concerning the status of } \\
\text { guideline adherence }\end{array}$ & $12(55 \%)$ & $10(45 \%)$ & $22(100 \%)$ & $3.813(.05)$ \\
\hline $\begin{array}{l}\text { - The departments/speciality report on the status of } \\
\text { implementation of guidelines that have high priority within } \\
\text { our hospital }\end{array}$ & $4(36 \%)$ & 7 (64\%) & $11(100 \%)$ & $0.138(.71)$ \\
\hline $\begin{array}{l}\text { - The departments/speciality report on the status of } \\
\text { implementation of all guidelines for medical specialists }\end{array}$ & $1(25 \%)$ & $3(75 \%)$ & $4(100 \%)$ & $0.473(.49)$ \\
\hline • Otherwise, namely & $2(13 \%)$ & $13(87 \%)$ & $15(100 \%)$ & $7.726(.005)$ \\
\hline Total & $16(41 \%)$ & $23(59 \%)$ & $39(100 \%)$ & \\
\hline
\end{tabular}

Table 4. Familiar with status of implementation versus experiencing problems with distribution of responsibility

\begin{tabular}{llll}
\hline \multirow{2}{*}{ Experiences with establishing responsibility } & \multicolumn{3}{c}{ Distribution of responsibility } \\
\cline { 2 - 4 } & Not problematic & \multicolumn{1}{c}{ Problematic } & Total \\
\hline $\begin{array}{l}\text { To what extent is the board of directors informed about the status of implementation of guidelines for medical specialists? It is informed of } \\
\text { the status of implementation of: }\end{array}$ & $6(55 \%)$ & $5(45 \%)$ & $11(100 \%)$ \\
- All guidelines & $6(30 \%)$ & $14(70 \%)$ & $20(100 \%)$ \\
- The guidelines that have priority within our hospital & $0(0 \%)$ & $0(0 \%)$ & $0(0 \%)$ \\
- Not one guideline & $4(50 \%)$ & $4(50 \%)$ & $8(100 \%)$ \\
- Otherwise, namely & $16(41 \%)$ & $23(59 \%)$ & $39(100 \%)$ \\
Total & & & \\
\hline
\end{tabular}




\subsection{Opportunities for improvement}

Firstly, the participants received Likert scale questions on the opportunities for improvement around guidelines. They agreed (95\%) that a clean-up action is needed to determine which guidelines are invalid (e.g. due to new improved guidelines, the guideline is no longer feasible or does not contribute to better quality of care). Also, they agreed (92\%) that hospitals should be able to defer the implementation of clinical guidelines beyond a predefined deadline, assuming that they provide a good justification. Furthermore, participants agreed (87\%) that hospital representatives should be involved in the development of guidelines to encourage guideline developers to pay attention to the preconditions for implementation. Seventy percent agreed that a large number of guidelines for medical specialists has a negative impact on their intrinsic motivation for their profession. More than two-thirds agreed that guidelines receive more attention if they are strictly enforced. More than $60 \%$ stated that the Inspectorate does not permit a hospital to decide that certain guidelines for medical specialists are not implemented, even if well argued (from the perspective of the hospital).

Secondly, the participants were asked in an open comment field about the main opportunities for improvements that they see. Of $82 \%$ of the participants who responded to the questions on possible improvements, the majority stated that the main opportunity to improve the situation is a central national database/portal with all up-to-date guidelines, whereby changes and news are distributed directly to hospitals and other stakeholders. They said that an overview is necessary to ensure that the collection of guidelines is well organised, to avoid duplication, to reduce the number of guidelines and to prioritise based on the risks for quality of care. Guidelines should include certain criteria such as distinct organisational and financial conditions, user-friendly layout, criteria for the expiry of guidelines and the availability of a summary of each guideline. It should be clearly stated which parts are mandatory and which parts are optional. Participants revealed that a distinction is necessary between (parts of) guidelines that aim to provide guidance for professionals and (parts of) guidelines that are used for enforcement for which hospital boards are held accountable. One participant stressed that it is important that major national stakeholders restrict themselves to the mandatory guidelines to avoid different institutions having dissimilar requirements regarding medical specialists' guidelines. Some participants stated that it is an opportunity to focus on the organisational impact in relation to risk management between the number of guidelines and the impact and workability in practice. A clear division of responsibilities for medical specialists and the board of directors should be regulated by the guidelines themselves.

\section{Discussion}

In this research, we examined how Dutch boards of directors of hospitals dealt with guideline adherence. Overall, our study revealed a valuable insight into how boards of directors of general and specialist hospitals arrange the responsibilities for guideline adherence within their organisation, how they deal with guidelines for medical specialists and what opportunities exist for improvement.

\subsection{Responsibilities for adherence and experience of problems}

Boards of directors of hospitals have the responsibility for the adoption of all quality standards. Therefore, it is imperative that they are able to oversee all of the guidelines, ensure adherence to the guidelines by all specialities, and also strive that there is for a smooth transition within and across the different units within their hospital organisation. This is particularly important for them to be able to understand the dynamics and also implement the guidelines optimally within the hospital settings. This process fits within the logic of the General System Theory.

Boards experience challenges in arranging responsibilities for adherence within their organisation. As mentioned in the Introduction, it is a new challenge for boards of directors to be responsible for guideline adherence for medical specialists. A large number (79\%) of the participants agreed that the board of directors was ultimately responsible for non-discipline-specific guidelines compared to disciplinespecific guidelines (56\%). The participants stated that in an ideal situation the ultimate responsibility of the board of directors would decrease and the responsibility of the medical specialists would increase. This contradicts with the prevailing views in Dutch politics and the current policies on hospital governance. The division of responsibilities between medical specialists and management is an important issue in the occurrence of incidents in health care. It is still unclear how to monitor supervision when it comes to aspects of the responsibility of all stakeholders. ${ }^{[10]}$

The results show that there is a gap between the desired and the actual situation; $97 \%$ of the participants stated that it is important that hospitals adhere to the guidelines for medical specialists while only $42 \%$ stated that this is feasible. To allow adherence to work according to the General Systems Theory, it is essential that a hospital receives all input, agrees with it and is able to adhere to it. At present, only $28 \%$ of the boards of directors are informed of the status of implementation of all guidelines. Hospitals require a systematic input of guidelines for hospitals, where all applicable 
medical guidelines are taken into account.

In this study, we see that the problems of boards of directors are diverse: it is impossible to verify adherence, an overview of guidelines is missing, and too many guidelines exist. It is interesting to see that while nearly everyone thought that it was important to adhere to guidelines, half of them agreed that it was not feasible. For future research, we need to widen our focus from hospitals to the health care system at large, since the hospital is a part of the health care system, which is a larger system. This study shows that hospitals are influenced by Inspectorate enforcement: participants used Inspectorate enforcement and the results to guarantee adherence to guidelines for medical specialists. Guidelines with enforcement receive more attention within a hospital. According to other studies, we need to be careful that the emphasis on legislation, quantifiable information and enforcement does not evoke counteraction. ${ }^{[11,12]}$ Enforcement leads to top-down control and leaves little room for bottomup arrangements, which might provide better fitting answers to health problems. Ruan, Ma, Vo and Chiravuri stated that guidelines should be used as guidance rather than enforcement standards because wrong guideline use may result in patient harm. ${ }^{[13]}$

\subsection{How boards of directors of hospitals in the nether- lands deal with guidelines for medical specialists}

The study has shown that boards of directors are rather passive in disseminating and securing guideline adherence for medical specialists. Participants stated that they organised and oversaw adherence separately in the local units (decentralised) and that physicians, together with their professional groups, have a major role. When questioned about how they keep informed about implementation, the boards of directors mostly referred to external and internal audits and to their protocols. Here, the boards of directors actually wait for something to happen (reactive) rather than getting things done before they are asked for it (proactive), as they rely on checks rather than previously embedded pathways to adherence. The goal of the boards of directors seems to be: as much decentralisation as possible. The question is then under what circumstances does this lead to insufficiency? What has to be centrally coordinated? How can boards of directors organise decentralised adherence while still being able to bear their responsibility? A possible theoretical approach could be shared or distributed leadership which is useful in complex social problems with different stakeholders. The interests of the patient are central in distributed leadership, and the focus is on learning and negotiating instead of decision-making and implementation. ${ }^{[14]}$

The participants were also asked about what steps were taken Published by Sciedu Press if progress on guideline implementation was insufficient. They stated that they brainstormed with the internal stakeholders to put systems in place, demand accountability, address the insufficiency, and then support them in working towards improvements. Boards of directors revealed that questions about adherence were tackled collectively and that they searched for possible solutions together. The question is whether this fits into the realm of control of the boards of directors and whether they tackled it this way due to the lack of other options. Only a few participants mentioned enforcement, sanctions or supervision as a possible step for non-adherence, which is interesting as this is a way the boards of directors could take their responsibility. In this research, 22 participants stated that they consult the departments regularly concerning the status of guideline adherence, and twelve of those do not experience problems in the establishment of responsibilities. The boards of directors are living with a decentralised solution, where trust seems to be a key element in the relationship between the board and the medical specialists. In this research, we did not study how boards arrange insights into how departments organise and execute adherence. Further research would be interesting to investigate under what circumstances centralisation is necessary and what boards need to be justified in their confidence in trusting to the decentralised adherence solution. It would also be interesting to find out how much hospital infrastructure is devoted to guideline implementation and what the resource implications would be.

\subsection{Implementation of guidelines for medical specialists}

Participants reported differently on the process of implementation and its status. Eleven boards stated that they know the implementation status of all guidelines, and five of those experience problems in establishing responsibilities. Six boards of directors knew the implementation status of all guidelines and experience no problems in responsibility establishment. This is not a high number if we take into account that the board is ultimately responsible for guidelines. However, it is a high number if we take the answers from the open comments field into account. Here, boards of directors reported that they can hardly live up to this responsibility on their own as the medical specialists and other stakeholders have a professional responsibility to work according to the guidelines of their profession. Also, five boards of directors expressed that awareness is limited and one respondent pointed out: "The number of guidelines is so large that I do not dare to say that we are aware of all guidelines."

Results from another study revealed that we can learn from Sweden. The recommendations in their national guidelines are linked to a degree of priority which is used for decision- 
making and prioritisation. In the Netherlands, we could use a similar system in the national overview to set priorities. ${ }^{[15]}$ What is also interesting is that Sweden appoints healthcare decision makers as the primary target group of guideline users as the guidelines offer support for control and management. Their approach adds a substantially different element in the overall system, as priorities are introduced as an option for adherence management. "The objective is to promote the efficient use of healthcare resources, as well as their allocation on the basis of need and their management on the basis of systematic and transparent priorities."[16] It could be good to gain experience of the risk-based prioritisation approach in the Netherlands. ${ }^{[8]}$

\subsection{Perceived opportunities for improvement}

Our analysis on the manner in which hospitals are working on guideline adherence indicates that at this time, no adequate solution has been found to systematically ensure that a hospital operates in accordance with medical guidelines. Considering the problems experienced, hospitals cannot resolve the question as it is now manifested. We need to zoom out to create more distance to understand what is going on. At present, stakeholders work within their own systems: guideline developers in their system of producing and disseminating guidelines, the Inspectorate in their system of surveillance, and hospitals in their system of implementation.

What we need is networking between these systems with a helicopter focus - metaphorically speaking a helicopter needs to be launched. Where do the inputs for a hospital come from and what is the purpose of the sub-system that produces them? Such an analysis would include guideline development and enforcement as it is part of the wider quality system. An analysis would allow a possible reassessment of the goals and purposes of the quality system as a whole and its sub-systems. We are thus opening a new perspective to the debate. We would like to bring the debate forward, by including the surrounding systems of a hospital and we plan to deploy it in further research activities.

\subsection{Limitations}

Before interpreting our findings, several limitations should be considered. With this study, we were able to gather necessary information from the boards of directors. However, out of 116 hospitals, only 39 completed the survey. Although we have no reason to assume selection bias, we are unable to check to which extent these boards are representative of all Dutch hospital boards. The respondents had different roles in the hospital organisations. Members of boards of directors were asked to complete the survey, but also, other staff members filled in the survey which could lead to bias. For three questions, the open comments fields were coded and added to the original possible answers. Despite numerous pre-tests, the respondents could not place their answer in the existing categories. A possible bias lies in self-reporting as participants may not do what they say they do.

\section{Conclusions}

This paper has shown that boards of directors experience difficulties in the responsibility of medical guideline implementation. It offers recommendations for a thoughtful shift in the distribution of responsibility, as in a more desired situation the ultimate responsibility of the board of directors would decrease and the responsibility of the medical specialists would increase. If the board of directors is ultimately responsible they should be supported by a systematic input of all relevant and available guidelines to be able to organise adherence management.

\section{Authors contributions}

Two of the authors work in Zuyderland MC (LHKB and JOB), one is leading an independent consultancy firm (NJHWW) and the fourth one is Professor at Tilburg University and also involved in national quality policy at the National Health Care Institute (DD). An advisory committee supervised this research to assure the independence of this study.

\section{ACKNOWLEDGeMENTS}

The authors thank the participants of the study for freely giving their time. They also want to thank Cindy Rodigas for her contribution. This study and the salary for the first author were funded by Zuyderland Medical Centre and Nederlandse Vereniging van Ziekenhuizen (NVZ).

\section{CONFLICTS OF INTEREST Disclosure}

NJHWW is leading the development of a consultancy programme on hospital governance for Q! B.V., in which he holds a minority share. The other authors declare that they have no competing interests.

\section{REFERENCES}

[1] Pronovost PJ. Enhancing physicians' use of clinical guidelines. JAMA. 2013; 310(23): 2501-2. http://dx.doi.org/10.1001/j ama. 2013.281334

[2] Powell BJ, McMillen JC, Proctor EK, et al. A compilation of strategies for implementing clinical innovations in health and mental 
health. Medical Care Research and Review. 2011; 69(2): 123-57. http://dx.doi.org/10.1177/1077558711430690

[3] Schneider JL, Davis J, Kauffman TL, et al. Stakeholder perspectives on implementing a universal Lynch syndrome screening program: a qualitative study of early barriers and facilitators. Genetics in Medicine Genet Med. 2015; 18(2): 152-161. http://dx.doi.o $\mathrm{rg} / 10.1038 / \mathrm{gim} .2015 .43$

[4] Yano EM, Green LW, Glanz K, et al. Implementation and spread of interventions into the multilevel context of routine practice and policy: implications for the cancer care continuum. JNCI Monographs, 2012; 2012(44): 86-99. http://dx.doi.org/10.1093/jncimon ographs/lgs004

[5] Solberg LI. Guideline implementation: what the literature doesn't tell us. Joint Commission Journal on Quality Improvement. 2000; 26: 525-37. PMid: 10983293.

[6] Von Bertalanffy L. The meaning of General System Theory. General System Theory: foundations, development, applications. New York: George Braziller; 1968. 30-53 p.

[7] Laszlo E. System, structure, and experience: toward a scientific theory of mind (Vol. 1). Taylor \& Francis. 1969.

[8] Blume LHK, Weert NJHWV, Busari JO, et al. Optimal use of external demands in hospitals - a Delphi study from the Netherlands. BMC Health Services Research. 2016; 16(1): 1-9. PMid: 26897176. http://dx.doi.org/10.1186/s12913-016-1315-8

[9] Van Someren MW, Barnard YF, Sandberg JAC. The think aloud method: a practical guide to modelling cognitive processes. London: Academic Press; 1994.

[10] Inspectie voor de gezondheidszorg [IGZ]. Staat van de gezondheidszorg. De vrijblijvendheid voorbij. Sturen en toezichthouden op kwaliteit en veiligheid in de zorg. Den Haag, november 2009 http://www.igz.nl/zoeken/download.aspx?download=S taat+van+de+Gezondheidszorg+(SGZ) $+2009 \% 3 \mathrm{~A}+$ De+vrij blijvenheid+voorbij ·pdf

[11] Robben PBM. Toezicht in een glazen huis. Effectiviteit van het toezicht op de kwaliteit van de gezondheidszorg (Supervision in a glass house. The effectiveness of supervision on the quality of healthcare). Inaugurale lecture. Rotterdam: Erasmus University, Institute Beleid \& Management Gezondheidszorg; 2010.

[12] De Bont A, Jerak S, Zuiderent J, et al. Veiligheid in de zorg. Achtergrondstudie bij de Staat van de gezondheidszorg 2009 (Safety in care. Background study at the State of Health Care Report 2009). Rotterdam: Erasmus University Rotterdam, Institute of Health Policy \& Management; 2009.

[13] Ruan X, Ma L, Vo N, et al. Clinical practice guidelines: the more, the better? N A J Med Sci North American Journal of Medicine and Science. 2015; 8(2): 77. http://dx.doi.org/10.7156/naj ms. 2015. 0802077

[14] Voogt JJ, van Rensen ELJ, Noordegraaf M, et al. Medisch leiderschap ontrafeld (Unravelling medical leadership). Ned Tijdschr Geneeskd. 2015; 159: A9123. PMid: 26271171.

[15] Fredriksson M, Blomqvist P, Winblad U. Recentralizing healthcare through evidence-based guidelines - striving for national equity in Sweden. BMC Health Services Research. 2014; 14(1). http: //dx.doi.org/10.1186/s12913-014-0509-1

[16] The National Board of Health and Welfare. National Guidelines for Methods of Preventing Disease - summary. Retrieved September $4^{\text {th }}$, 2016. Available from: http://www.socialstyrelsen.se/nationalguideline s/nationalguidelinesformethodsof preventingdisease 